\title{
Research Square \\ Effect of Multilayer Configuration on Spectral Response of Thin Film TiO2/NiO Heterojunction Photodetector
}

Oday A. Hammadi ( $\sim$ odayata2001@yahoo.com )

Al Iraqia University

\section{Research Article}

Keywords: Thin films, Multilayer structure, Spectral response, Heterojunction

Posted Date: June 30th, 2021

DOI: https://doi.org/10.21203/rs.3.rs-599613/v1

License: (c) (1) This work is licensed under a Creative Commons Attribution 4.0 International License.

Read Full License 


\section{Abstract}

In this work, a multilayer design for the $\mathrm{TiO}_{2} / \mathrm{NiO}$ heterojunction device is proposed. In this design, layers of $\mathrm{TiO}_{2}$ nanostructures are consecutively deposited on layers of $\mathrm{NiO}$ nanostructures deposited on ITO substrates. This design was compared to the conventional design of thin film $\mathrm{TiO}_{2} / \mathrm{NiO}$ heterojunction device by measuring the spectral response of both designs in the spectral range of $200-1200 \mathrm{~nm}$. The proposed design showed increased response intensity by $14 \%$, narrowing spectral width by $23 \%$ and single peak of response at $440 \mathrm{~nm}$.

\section{Introduction}

Thin films still have their outstanding position in photonics and optoelectronics systems and networks due to the irreplaceable characteristics to be provided by the bulk structures [1-3]. Therefore, the research interests to thin films are continuously increased to achieve better characteristics those would develop the performance of the devices based on thin films [4-6].

As thin films are prepared by several different methods and techniques, many options are available for the designers of thin film devices. However, no single method or technique could produce thin films with the best characteristics. Therefore, continuous evaluation of thin films prepared by any method or technique may provide useful data for designers to choose the optimum for their requirements and applications $[1,3]$.

More than six decades when first thin film heterojunctions were fabricated. Despite, thin film heterojunctions are the basis of the most effective photonic and optoelectronic devices used in many modern technologies, mainly optical communications and biomedical engineering [7-10]. The combination of thin film physics and engineering has established such basis. However, new aspects of this combination are explored to produce new photonic and optoelectronic devices [11, 12].

Titanium dioxide and nickel oxide are among the most common metal oxide semiconductors due to their excellent characteristics clearly shown in the devices fabricated from them [13]. Research works are motivated to use them because of the excellent energy outline formed due to their energy band gaps (3.20 eV for $\mathrm{TiO}_{2}$ and $3.85 \mathrm{eV}$ for $\mathrm{NiO}$ ) $[14,15]$. The different types of electrical conductivity allowed to fabricate pn heterojunctions of very attractive characteristics. Furthermore, they uniquely show some features making them unbeatable by other metal oxide or compound semiconductors. Photocatalytic activity of titanium dioxide and electrochromic behavior of nickel oxide are examples [14].

Nanotechnology has revolutionized the thin film technology as the designers are making use of nanostructures and their features in addition to those of thin films. So, the ultra-fast response, ultra-high reliability, ultra-high efficiency, ultra-high compactness, high reproducibility and low production cost could be achieved at once $[7,8]$. Nevertheless, relatively simple ideas and inexpensive developments - those might not be seen before - still possible to design and produce new photonics and optoelectronics [9]. 
In this work, the multilayer configuration of $\mathrm{TiO}_{2} / \mathrm{NiO}$ thin film heterojunction is proposed to enhance the spectral response of photonic devices based on such heterostructure.

\section{Experimental Part}

A dc reactive magnetron sputtering system was used in this work to deposit titanium dioxide $\left(\mathrm{TiO}_{2}\right)$ and nickel oxide ( $\mathrm{NiO}$ ) thin films on indium-doped tin oxide (ITO) substrates. A closed-field unbalanced dualmagnetron assemblies were employed at both electrodes of plasma discharge system. Such assemblies enables highly homogeneous sputtering of titanium and nickel targets as well as homogeneous deposition of thon films on the substrates. Experimental details on the sputtering system used in this work can be found elsewhere [16-24].

The structural characterization tests, mainly x-ray diffraction (XRD), atomic force microscopy (AFM), scanning electron microscopy (SEM), and energy-dispersive $x$-ray (EDX) spectroscopy, have confirmed the formation of nanostructures from both materials $\left(\mathrm{TiO}_{2}\right.$ and $\left.\mathrm{NiO}\right)$. They have also confirmed the high structural purity of the prepared samples as no traces for other elements and compounds were found in the final products. The minimum nanoparticle size was $20 \mathrm{~nm}$ for $\mathrm{TiO}_{2}$ and $15 \mathrm{~nm}$ for $\mathrm{NiO}$. The deposition rates of $\mathrm{TiO} 2$ and $\mathrm{NiO}$ films shown in Fig. (1) were finely controlled due to the sputtering system stability.

Two multilayer structures shown in Fig. (2) were prepared in this work and their spectral response were compared to introduce the advantages of the proposed design as a heterojunction device. In the first structure, a $\mathrm{TiO}_{2}$ thin film of $150 \mathrm{~nm}$ thickness was deposited on the ITO substrate after deposition time of 105 minutes. Then, a $\mathrm{NiO}$ thin film of $150 \mathrm{~nm}$ thickness was deposited on the $\mathrm{TiO}_{2}$ layer after deposition time of 90 minutes.

In the second structure, a $\mathrm{NiO}$ thin film of $80 \mathrm{~nm}$ thickness was deposited on the ITO substrate after deposition time of 30 minutes. Soon after, two consecutive layers of NiO of 105 and $120 \mathrm{~nm}$ were deposited after deposition time of 45 and 60 minutes, respectively. Then, three layers of $\mathrm{TiO}_{2}(105,75$ and $40 \mathrm{~nm}$ ) were consecutively deposited after deposition times of 60,45 and 30 minutes, respectively.

Thin films of aluminum were deposited on the top surface of the prepared samples to act as electrodes for the electrical measurements. The optoelectronic measurements were carried out using different light sources with different wavelengths and intensities. The spectral response of the prepared samples was measured in the spectral range 200-1200 nm using a monochromator equipped with ceramic heater light source and chopper.

\section{Results And Discussion}

Figure (3) shows the spectral response of both configurations of multilayer thin film structures prepared in this work. The conventional configuration containing of one layer of $\mathrm{NiO}$ deposited on one layer of $\mathrm{TiO}_{2}$ shows two peaks at 400 and $460 \mathrm{~nm}$ with spectral width of $300 \mathrm{~nm}$, while the other configuration 
containing of three layers of $\mathrm{NiO}$ deposited consequently on three layers of $\mathrm{TiO}_{2}$ shows single peak at $440 \mathrm{~nm}$. There three observations in these spectra, they are (1) disappearance of the two peaks at 400 and $460 \mathrm{~nm}$ and appearance of new peak at $440 \mathrm{~nm}$, (2) increase in the intensity by 14\%, and (3) narrowing of spectral width by $23 \%$.

As the $\mathrm{TiO}_{2}$ layers are receiving the incident radiation before $\mathrm{NiO}$ layers, then they may act as filtration layers to transmit the photons whose wavelengths are within the absorption band of $\mathrm{TiO}_{2}$, which is narrower than that of $\mathrm{NiO}$. Therefore, the absorption peak of $\mathrm{NiO}$ and corresponding response at $400 \mathrm{~nm}$ disappeared from the spectral response spectrum of the multilayer configuration. As the absorption cross section of the $\mathrm{TiO}_{2}$ nanoparticles is highly increased with decreasing particle size, then the absorption peak and hence the spectral response at $460 \mathrm{~nm}$ is shifted towards shorter wavelengths (440nm) as photons of higher energies are efficiently absorbed in the $\mathrm{TiO}_{2}$ layers as well as in the heterojunction region.

When the $\mathrm{TiO}_{2}$ and $\mathrm{NiO}$ films are deposited as in the conventional configuration with thickness of 220 and $300 \mathrm{~nm}$, respectively, the opportunity for the nanoparticles to get bigger and aggregate is reasonably available. Therefore, the radiation should traverse throughout these regions of aggregated particles before reaching the heterojunction. Consequently, this would limit the number of photons to be absorbed. In the multilayer configuration, the thickness of each layer is smaller than that in the conventional configuration. Therefore, the opportunity for the nanoparticles to get bigger and aggregate is relatively lower. The radiation traverses faster throughout the $\mathrm{TiO}_{2}$ layers to reach the heterojunction with larger number of photons and hence higher absorbance. This may interpret the higher intensity of spectral response in the multilayer configuration.

The narrowing observed in the spectral width may be attributed to the high homogeneity in the absorption of incident photons by the nanoparticles that normalizes the absorption in the heterojunction region.

\section{Conclusion}

In concluding remarks, a multilayer design for the $\mathrm{TiO}_{2} / \mathrm{NiO}$ heterojunction device is proposed. In this design, layers of $\mathrm{TiO}_{2}$ nanostructures are consecutively deposited on layers of $\mathrm{NiO}$ nanostructures deposited on ITO substrates. This design is based on the fine control of deposition rate of $\mathrm{TiO}_{2}$ and $\mathrm{NiO}$ films. This design was compared to the conventional design of thin film $\mathrm{TiO}_{2} / \mathrm{NiO}$ heterojunction device by measuring the spectral response of both designs in the spectral range of 200-1200 nm. The proposed design showed increased response intensity by $14 \%$, narrowing spectral width by $23 \%$ and single peak of response at $440 \mathrm{~nm}$. The proposed design is simple, low cost and efficient for heterojunction devices.

\section{Declarations}

\section{Availability of data and materials}


The author declares that all data and materials included in this work are available.

\section{Funding}

The author declares that this work was not supported by any other entity or institution.

\section{Conflict of Interest}

The author declares that he does not have any conflict of interest related to this work.

\section{Acknowledgements}

N/A

\section{References}

1. Shainline, J.M.: Optoelectronic intelligence. Appl. Phys. Lett. 118, 160501 (2021)

2. Wasa, K., Kitabatake, M., Adachi, H.: Thin Film Materials Technology: Sputtering of Compound Materials. William Andrew Inc. p. 139, 116(106), 103 (2004)

3. Kneissl, M.: "A Short Introduction to Semiconductor Nanophotonics", in Semiconductor Nanophotonics, ed. M., Kneissl, A., Knorr, S., Reitzenstein, Hoffmann, A. (eds.), Springer, pp. 1-11 (2020)

4. Ohring, M.: The Materials Science of Thin Films, p. 79, p. 112. Academic Press (1992)

5. Stenzel, O.: The Physics of Thin Film Optical Spectra, p. 91. Springer (2005)

6. Ginley, D.S.: Handbook of Transparent Conductors, p. 437. Springer (2010)

7. Goddard, W.A., et al.: Handbook of Nanoscience, Engineering and Technology, p. 65. CRC Press (FL (2003)

8. Bhushan, B.: Springer Handbook of Nanotechnology, p. 181. Springer-Verlag, Berlin (2004)

9. Cheng, J., et al.: Recent Advances in Optoelectronic Devices Based on 2D Materials and Their Heterostructures. Adv. Opt. Mater. 7(1), 1800441 (2019)

10. Martin, P.M.: Handbook of Thin Film Deposition Techniques, p. 4. Elsevier (2010)

11. Frisenda, R., et al.: Atomically thin $\mathrm{p}-\mathrm{n}$ junctions based on two-dimensional materials. Chem. Soc. Rev. 47(9), 3339-3358 (2018)

12. Ziental, D., et al.: Titanium Dioxide Nanoparticles: Prospects and Applications in Medicine. Nanomater. 10, 387-331 (2020)

13. Safi, I.: Recent aspects concerning DC reactive magnetron sputtering of thin films: A review. Surf. Coat. Technol. 127, 203-219 (2000) 
14. Ezema, F.I., Ekwealor, A.B.C., Osuji, R.U.: Optical properties of chemical bath deposited nickel oxide $\left(\mathrm{NiO}_{\mathrm{x}}\right)$ thin films. Superficies y Vacío 21(1), 6-10 (2008)

15. Al-Maliki, F.J., Al-Oubidy, E.A.: Effect of gas mixing ratio on structural characteristics of titanium dioxide nanostructures synthesized by DC reactive magnetron sputtering. Physica B: Cond. Matter $555,18-20$ (2019)

16. Hammadi, O.A., et al.: Operation Characteristics of a Closed-Field Unbalanced Dual-Magnetrons Plasma Sputtering System. Bulg. J. Phys. 41(1), 24-33 (2014)

17. Hammadi, O.A., Khalaf, M.K., Kadhim, F.J.: Fabrication of UV Photodetector from Nickel Oxide Nanoparticles Deposited on Silicon Substrate by Closed-Field Unbalanced Dual Magnetron Sputtering Techniques. Opt. Quantum Electro. 47(12), 3805-3813 (2015)

18. Hammadi, O.A., Khalaf, M.K., Kadhim, F.J.: Fabrication of UV Photodetector from Nickel Oxide Nanoparticles Deposited on Silicon Substrate by Closed-Field Unbalanced Dual Magnetron Sputtering Techniques. Opt. Quantum Electron. 47(12), 3805-3813 (2015)

19. Hammadi, O.A., Naji, N.E.: Electrical and spectral characterization of CdS/Si heterojunction prepared by plasma-induced bonding. Opt. Quantum Electron. 48(8), 375-381 (2016)

20. Hammadi, O.A., Khalaf, M.K., Kadhim, F.J., "Fabrication and Characterization of UV Photodetectors Based on Silicon Nitride Nanostructures Prepared by Magnetron Sputtering", Proc. IMechE, Part N, J. Nanomater., Nanoeng. Nanosys., 230(1): (2016) 32-36

21. Hammadi, O.A., Khalaf, M.K., Kadhim, F.J., "Fabrication and Characterization of UV Photodetectors Based on Silicon Nitride Nanostructures Prepared by Magnetron Sputtering", Proc. IMechE, Part N, J. Nanoeng. Nanosys., 230(1): (2016) 32-36

22. Al-Oubidy, E.A., Al-Maliki, F.J.: Effect of Gas Mixing Ratio on Energy Band Gap of Mixed-Phase Titanium Dioxide Nanostructures Prepared by Reactive Magnetron Sputtering Technique. Iraqi J. Appl. Phys. 14(4), 19-23 (2018)

23. Turki, R.H., Hameed, M.A.: Spectral and Electrical Characteristics of Nanostructured $\mathrm{NiO} / \mathrm{TiO}_{2}$ Heterojunction Fabricated by DC Reactive Magnetron Sputtering. Iraqi J. Appl. Phys. 16(3), 39-42 (2020)

24. Faisal, S.H., Hameed, M.A.: Heterojunction Solar Cell Based on Highly-Pure Nanopowders Prepared by DC Reactive Magnetron Sputtering. Iraqi J. Appl. Phys. 16(3), 27-32 (2020)

\section{Figures}



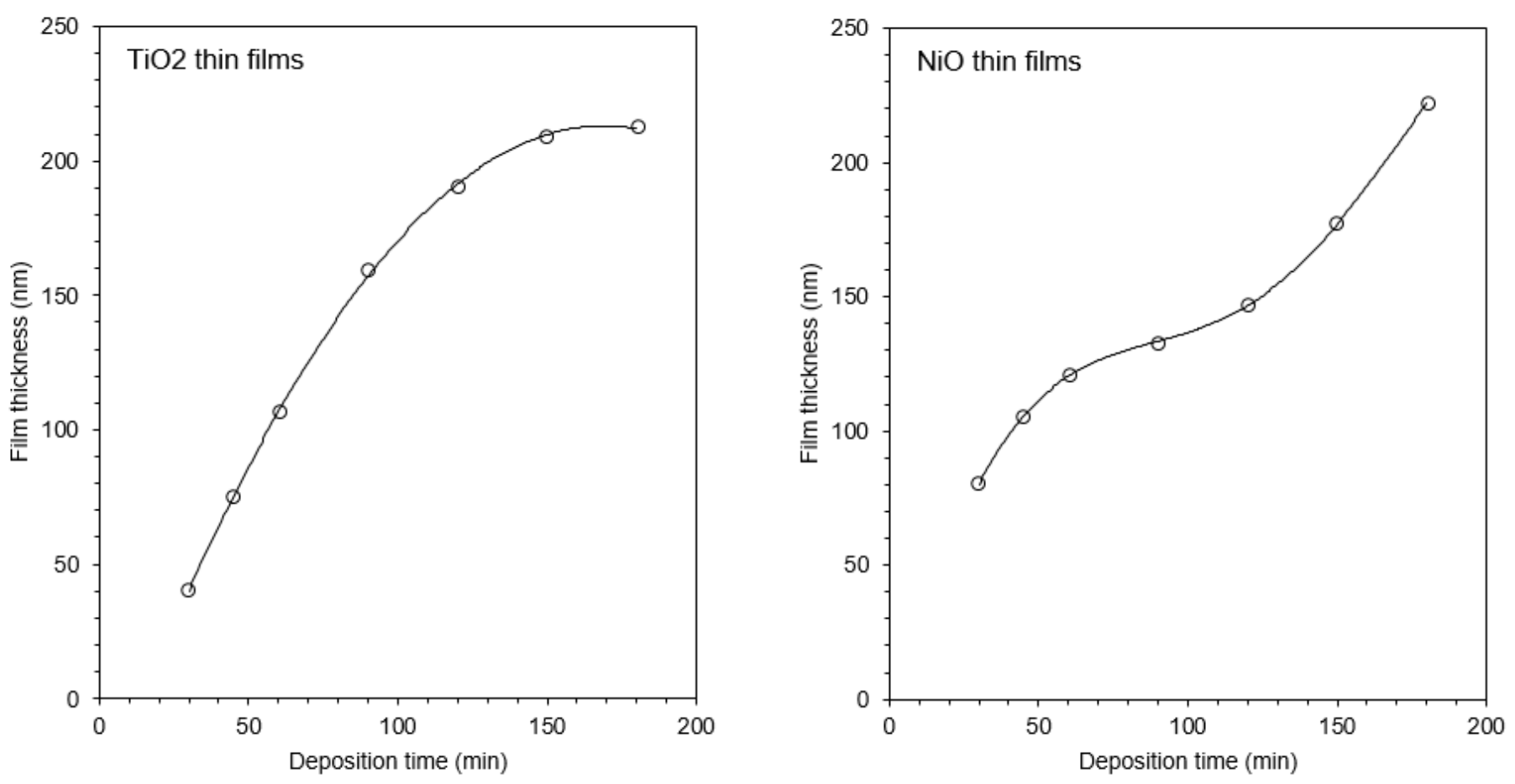

Figure 1

Deposition rates of $\mathrm{TiO} 2$ and $\mathrm{NiO}$ film deposition in this work 


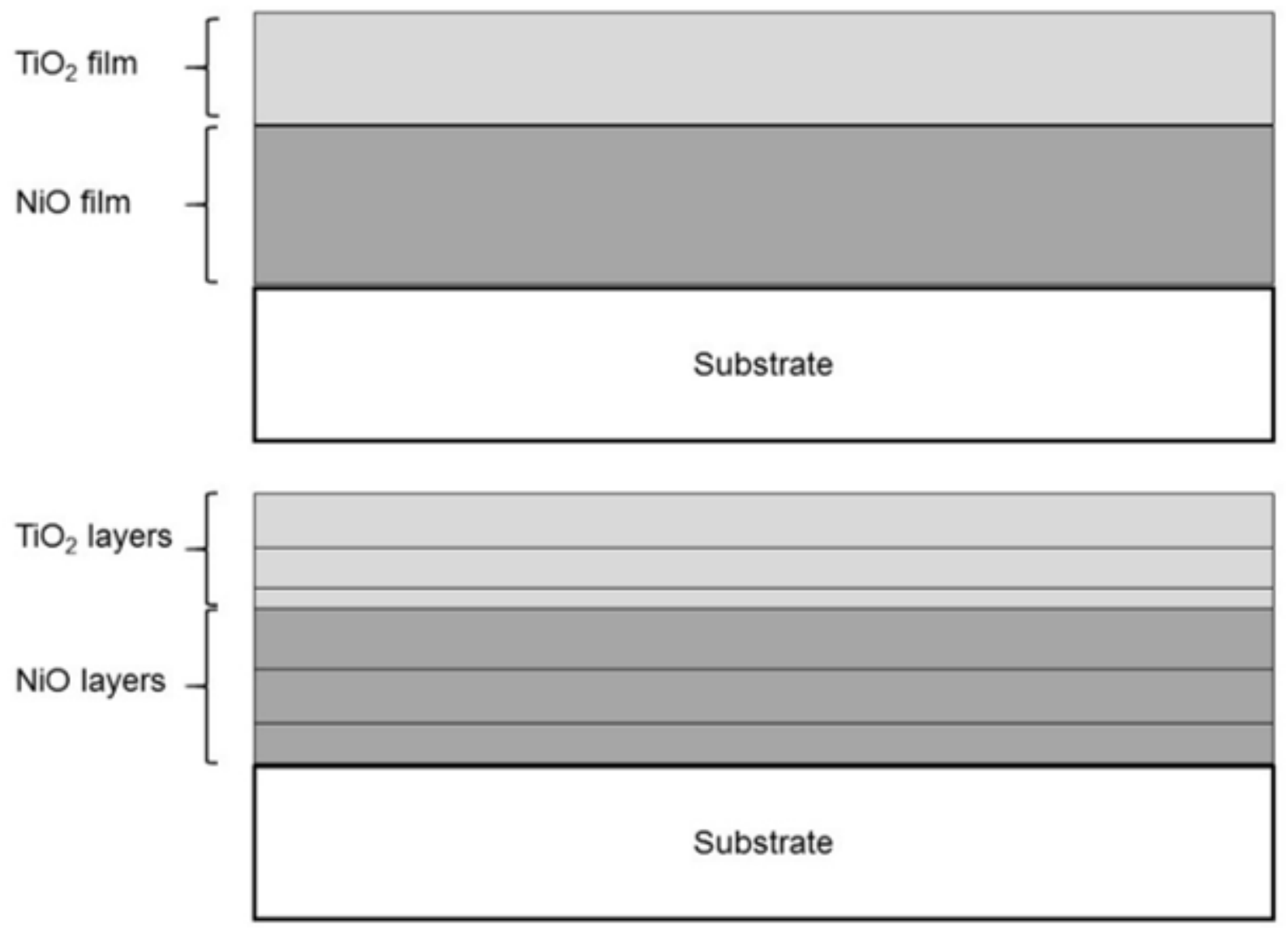

Figure 2

The two multilayer structures prepared in this work 


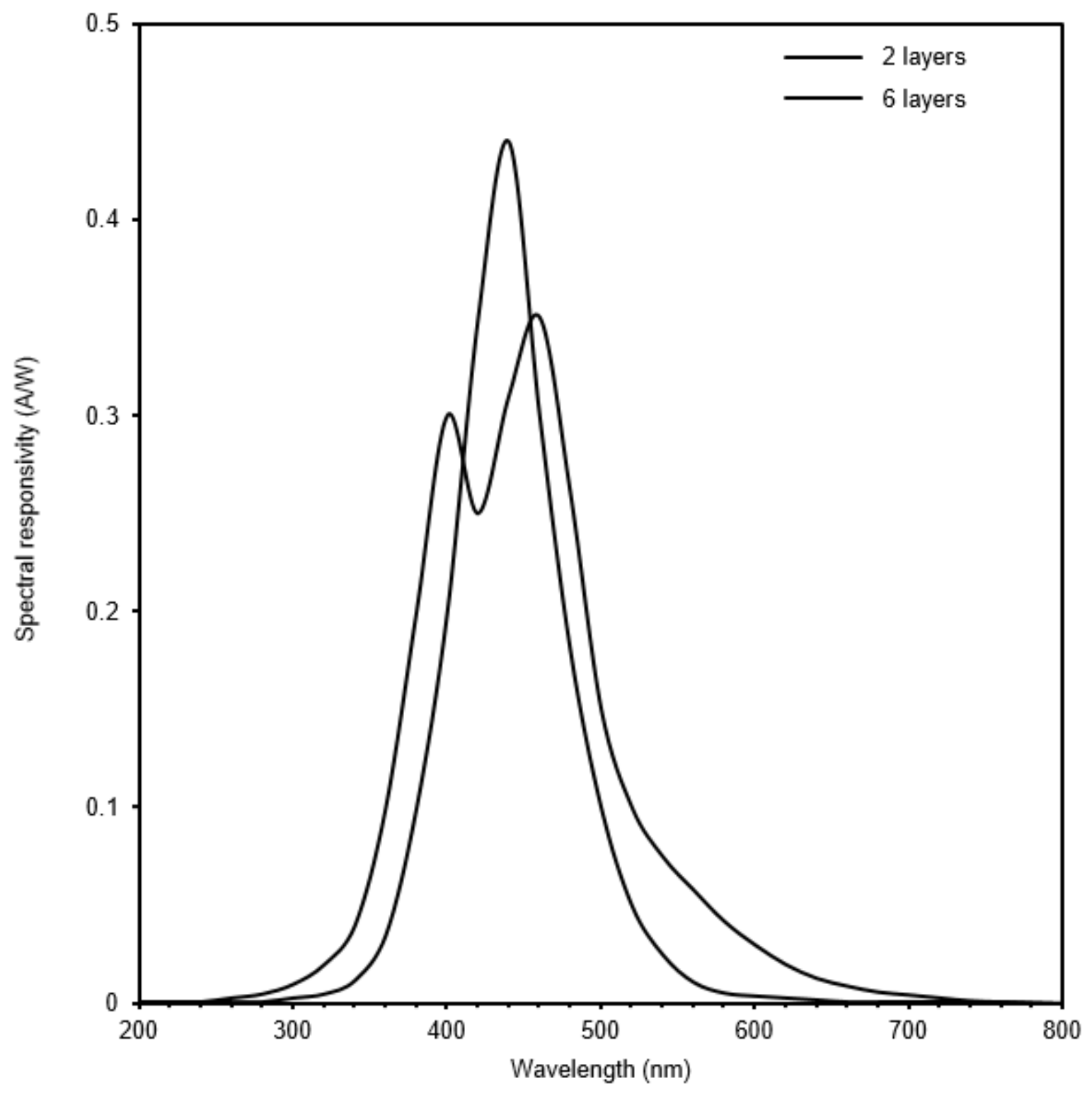

Figure 3

Spectral response of the multilayer structures prepared in this work 